\title{
Determination of dependencies of dehydration of thermal power plants' ash and slag waste from equipment parameters
}

\author{
Valentyna Cholyshkina ${ }^{1, *}$, and Serhii Kostyria ${ }^{1}$ \\ ${ }^{1}$ Institute of Geotechnical Mechanics named by N. Poljakov of National Academy of Sciences of \\ Ukraine, 49005, Dnipro, Simferopolska Str., 2a, Ukraine
}

\begin{abstract}
Complex processing of ash and slag from coal-fired thermal power plants attracts a lot of attention. Waste processing will reduce the load on existing storage facilities, to return unburned coal to the boilers of power plants, to obtain a valuable raw material resource for construction, ferrous and non-ferrous metallurgy. At all thermal power plants of Ukraine utilization and storage of ash and slag is carried out by hydraulic method. Therefore, for all processing technologies relevant the dehydration of finedisperse raw material. The article presents the results of laboratory tests of a new device for dehydration of ash and slag waste. It uses a set of influences on raw material: the overlay of vibration oscillations, the electric field and vacuumizing. By the method of pair linear correlations it is obtained that the dependence of moisture on each of the variable parameters has a weak nonlinear character. The exact and approximate multiple regression equations for the practical assessment of moisture under the combined action of all variable factors are obtained. With the size of the raw material $+0.63-0.05 \mathrm{~mm}$, it allows to reduce the moisture from 30 to $9 \%$.
\end{abstract}

\section{Introduction}

In the modern world, the process of electricity production at thermal power plants (TPP) is carried out by burning fine coal, while a huge amount of ash and slag is formed. Thus, for a typical thermal power plant with a capacity of $1295 / 1540 \mathrm{MW}, 3500 \mathrm{Gcal} / \mathrm{hr}$, the amount of waste is from 120 to 1700 thousand tons per year, depending on the ash content (level) of the burned coal $[1,2]$. Ash removal from coal combustion (fly ash) and slag is carried out on ash dumps by hydraulic method in the form of water pulp.

At present, almost all the ash storage facilities are overloaded, but the organization of new ones is problematic due to the lack of free areas of waste land near the existing thermal power plants. Growing storage areas cause environmental problems due to pollution of groundwater with alkaline highly mineralized filtration waters of dumps.

In addition, TPP under the terms of its schedule work with variable load during the year. Because of this, the area of ash dumps has mobile boundaries, which causes active dusting, leaching (washout) by precipitation. Because of this, dusting occurs, which causes

*Corresponding author: chel.valenti@gmail.com 
environmental pollution [1-3].

Processing of ash and slag waste of TPP attracts more attention because this product is a valuable technogenic raw material [2-7]. The most relevant is work on the creation of a comprehensive waste-free technology for the extraction of silicate fraction, metal (in the form of iron splices) and unburned coal. Each of these products has industrial interest.

As an illustration, we give a typical example of indicators of ash and slag waste (fly ash) of the Novo-Kramatorsk TPP [3]. This material was used by us for experimental studies, which are reflected below in this article.

For a correct analysis of the control points of TPP ash storage were selected six samples. After drying, the samples were dispersed into size classes. In each class, after firing (roasting) and burning out of carbon by magnetic separation, the output of the magnetic fraction - intergrown pieces of iron - was determined. The results of the analysis, averaged over six samples, are presented in the Table 1.

Table 1. Granulometric composition and the weight output of aggregates (intergrown pieces) of iron in the dump fly ash.

\begin{tabular}{|c|c|c|}
\hline $\begin{array}{c}\text { Particle size classes, } \\
\mathrm{mm}\end{array}$ & Output, \% & $\begin{array}{c}\text { Output of aggregates of } \\
\text { iron, } \%\end{array}$ \\
\hline Source material & 100 & 83 \\
\hline$-0.63+0.25$ & 8 & 50 \\
\hline$-0.25+0.1$ & 31 & 81 \\
\hline$-0.1+0.05$ & 38 & 87 \\
\hline-0.05 & 23 & 94 \\
\hline
\end{tabular}

Table 2 shows the ash distribution in the specified size classes for each sample.

Table 2. Silicates content of dump fly ash.

\begin{tabular}{|c|c|c|c|c|c|c|}
\hline \multirow{2}{*}{$\begin{array}{c}\text { Particle } \\
\text { size } \\
\text { classes, } \\
\text { mm }\end{array}$} & \multicolumn{7}{|c|}{ Silicates content, \% } \\
\cline { 2 - 7 } & $\begin{array}{c}\text { Sample } \\
1\end{array}$ & $\begin{array}{c}\text { Sample } \\
2\end{array}$ & $\begin{array}{c}\text { Sample } \\
3\end{array}$ & $\begin{array}{c}\text { Sample } \\
4\end{array}$ & $\begin{array}{c}\text { Sample } \\
5\end{array}$ & $\begin{array}{c}\text { Sample } \\
6\end{array}$ \\
\hline$-0.63+0.25$ & - & - & - & - & - & 32.03 \\
\hline$-0.25+0.1$ & 38.7 & 48.54 & 72.46 & 83.54 & - & 50.21 \\
\hline$-0.1+0.05$ & 50.0 & 55.73 & 78.21 & 87.19 & 76.53 & 60.61 \\
\hline-0.05 & 79.9 & 83.95 & 89.2 & 90.29 & 87.7 & 81.8 \\
\hline
\end{tabular}

As can be seen from Tables 1 and 2, intergrown pieces of iron and unburned carbon are unevenly distributed by size classes. The lowest ash content and correspondingly high carbon content are observed in the upper classes starting from $0.63 \mathrm{~mm}$ and up to $0.1 \mathrm{~mm}$ inclusive. With a decrease in the size, the carbon content naturally decreases (Table 2). The number of rich in carbon classes is large enough, their output is $39 \%$ of the total mass of raw materials (Table 1). Extraction and return of unburned coal to the thermal power plant boilers will compensate up to $20 \%$ of the daily needs of the thermal power plant in coal, 
which is estimated at about 1.5 thousand tons, as well as will reduce the purchase of coal and transport costs for delivery [3]. One of the reasons for the profitability of the technology for the extraction of waste components-coal, metal fraction and silicate part, is that all components are finely dispersed. This eliminates the expensive operations of additional grinding of raw materials in preparation for magnetic or electrical separation and is convenient for the direct use of coal and silicates.

Modern research on the processing of ash and slag waste is aimed at the development and improvement of technology and equipment, the expansion of the application of ash [17]. For example, about 300 technologies of processing and use of ash and slag waste are known [4], however in the majority of them we are talking about the dry product - the fly ash which was not in contact with water. Dry storage of ash and slag waste is a promising method, which is an alternative to hydraulic waste disposal and wet storage $[5,6]$. It consists in the pneumatic collection of ash and dehydration of slag in the hydraulic removal from the furnaces of boilers. Dry storage of ash and slag eliminates the costly barrier dams and special anti-filtration screens in the construction of dumps. The main negative impact on the environment is dusting during loading and transportation. However, today dry storage of ash waste abroad is used in small volumes, and in Ukraine is not used at all [5-7].

All coal thermal power plants and thermal power plants of Ukraine have a hydraulic ash removal system. Therefore, in order to use huge reserves of ash storages for processing, at the first stage it is necessary to solve the problem of dehydration of fine raw materials. To solve it, we improve the design of centrifuges, screens and hydrocyclones, as well as develop devices with any additional effects, for example, pulsed [8].

As one of the solutions to the problem of dehydration of fine material the Institute of geotechnical mechanics developed a device for dehydration of complex action [9]. Its appeal lies in the simultaneous use of three methods of dehydration: vibration, vacuum and electrokinetic (electroosmotic). This article describes the results of the tests of this device in the dehydration of wastes Novo-Kramatorsk thermal power plant (Table 1,2) and theoretical analysis of experimental data.

\section{Experimental studies}

The dehydrating device [9] is made in the form of a box with a mesh bottom (Fig. 1).
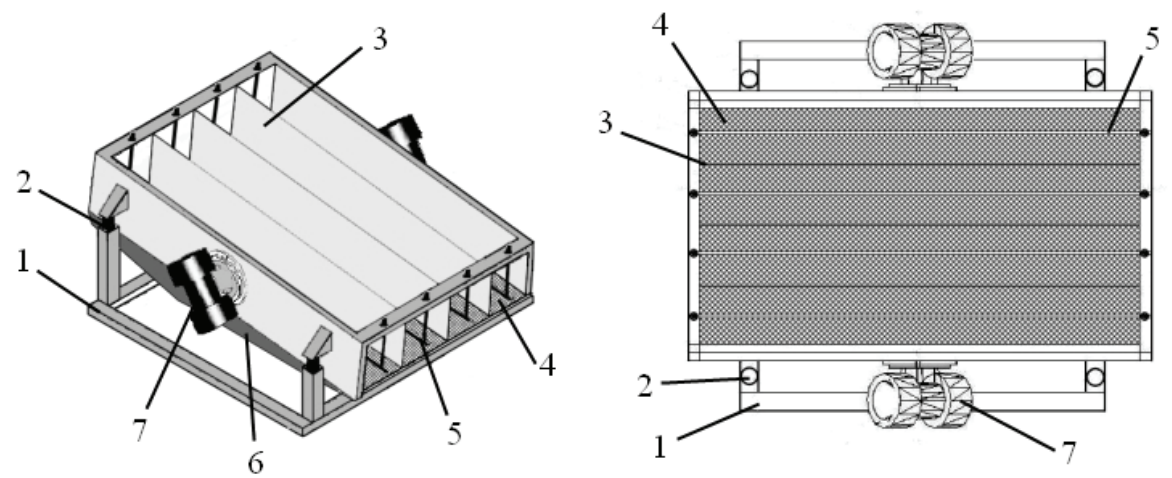

Fig. 1. General view of the dehydrating device: 1 - support frame; 2 - rubber shock- absorbers; 3 partition; 4 - perforated surface; 5 - conductive rod; 6 - vacuum chamber; 7 - inertial vibration exciter.

With the help of vibration, which is created by an inertial vibration exciter (7), there is a continuous movement of the bulk wet mass on an inclined perforated (mesh) surface. The removed liquid passes through the rock mass layer towards the perforated surface and is 
removed to the drain. The rate of liquid seepage is controlled and can be increased by the creation of the underpressure in a vacuum chamber (6). In this case, air thrust generated by vacuuming will act on the liquid, in addition to gravitational forces.

The movement of the material on the working surface occurs in constant contact with the electrodes (5), which are made in the form of conductive rods. The imposition of a constant electric field causes the phenomena of electroosmosis and electrophoresis. In this case, there is a movement of negatively charged colloidal and fine clay particles to the positive pole of the source, and water - to the negative. By removing excess water from the cathodes due to electrophoresis, it is possible to reduce the moisture content of the material and its compaction. Electro-osmosis leads to a decrease in the capillary and pore humidity due to the weakening of surface tension of the liquid in the pore channels.

Experimental studies of the process of complex dehydration of fly ash were aimed at determining the parameters of the device affecting the final moisture $W$. The initial moisture content of the material was $W_{0}=30 \%$. The following operating and design parameters of the device were changing: the area of the perforated surface, the angle of inclination of the working body of $\alpha$, the oscillation frequency of the exciter $\omega$ (rpmrotation per minute), the magnitude of the disturbing force (stress) $F$ the exciter, the voltage of the electric field $U$, the pressure in the vacuum chamber $P$. During the experiments, one of the parameters was initially varied for the other fixed ones. Then the experiments were repeated for another variable and other fixed parameters. Thus, the pair correlation dependences of moisture on each of the four variable parameters were obtained (Fig. 2).
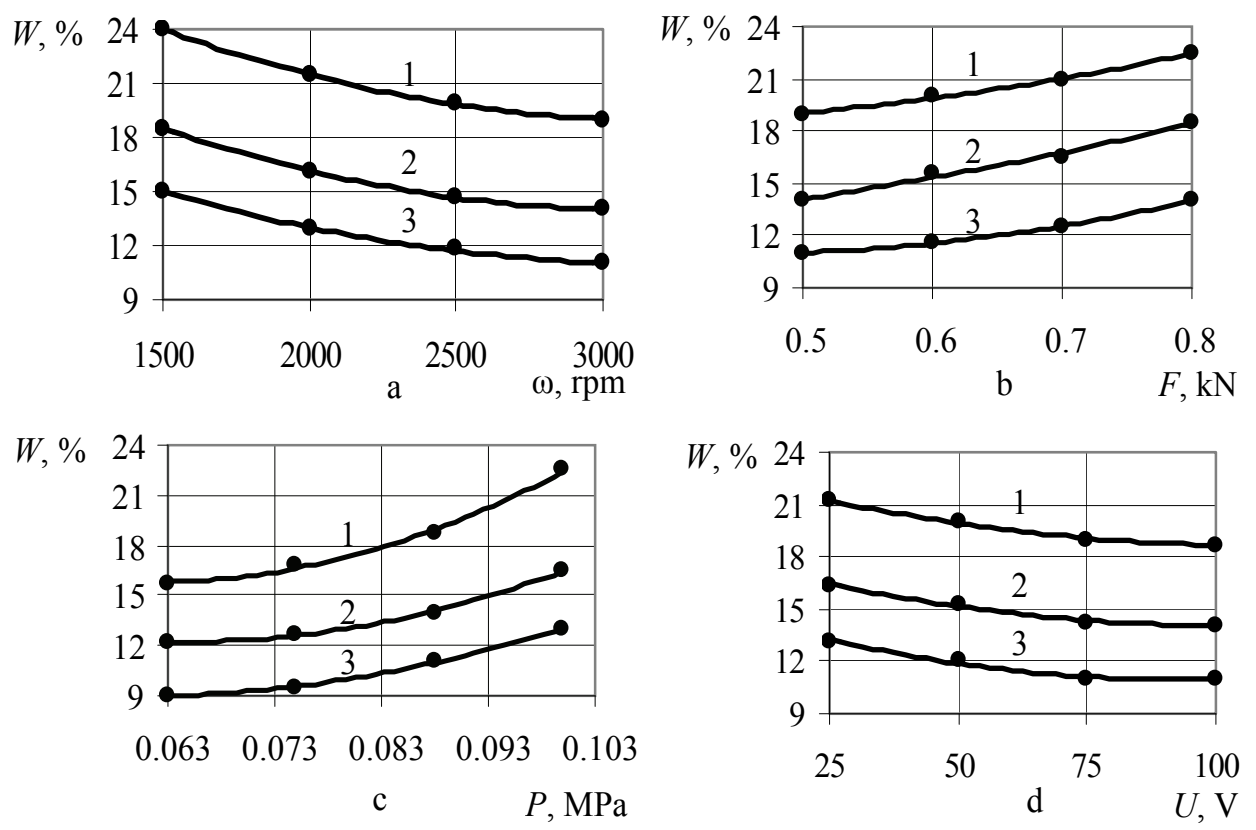

Fig. 2. Dependence of moisture on the parameters of the device of complex dehydration of ash and slag waste: $\mathrm{a}$ - from the intensity of the electric field; $\mathrm{b}$ - from the vibration frequency; $\mathrm{c}$ - from the pressure in the vacuum chamber, $\mathrm{d}$ - from the disturbing force of the vibration exciter. Working surface area $S: 1-0.08 ; 2-0.56 ; 3-1.12\left(\mathrm{~m}^{2}\right)$.

As shown in Figure 2 all the dependencies have a weak non-linear character. Each of the parameters has a close correlation with humidity, the pair correlation coefficient for them was not lower than 0.985 . Further analysis was to establish the dependence of the indicators of dehydration from all the influencing parameters. 


\section{Theoretical studies}

To obtain the dependence of moisture on all variable factors, a database of experimental data was prepared, which included 39 experiments. Constants in all experiments were the initial moisture of the samples $W_{0}=30 \%$ and the angle of inclination of the working body $\alpha=5^{\circ}$. The experiments were performed for three values of the perforated surface area on which the dryable product was placed: $S=0.08 ; 0.56$ and $1.12 \mathrm{~m}^{2}$. Four variable factors for each value of the square were changed within the following limits:

- vibration frequency of the vibration exciter $\omega=1500-3000 \mathrm{rpm}$, in increments $500 \mathrm{rpm}$;

- the magnitude of the disturbing force of the vibration exciter $F=0.5-0.8 \mathrm{kN}$, in increments $0.1 \mathrm{kN}$;

- the intensity of the electric field $U=25-100 \mathrm{~V}$, in increments $25 \mathrm{~V}$.

- the pressure in the vacuum chamber $P=0.063-0.1 \mathrm{MPa}$, in increments $0.012 \mathrm{MPa}$;

It was found that with different combinations of device parameters the moisture can be reduced from 30 to $9 \%$. The linear correlation of each of the parameters with moisture is weakly nonlinear.

To construct a generalized mathematical model of moisture changes from variables $S$, $\omega, F, U, P$, the method of regression analysis using the built-in functions of the statistical data processing program "SPSS Statistics" was used [10]. The degree of approximation of regression equations was estimated by the value of the square of the correlation coefficient $R^{2}$.

First of all, a qualitative assessment of the impact on the humidity of each individual factor in their joint action was carried out. For this purpose, a simple linear regression dependence was constructed $W=f(S, \omega, F, U, P)$. In the program SPSS Statistics option «Enter» was used - forcible inclusion of all variables (variable factors). The equation is obtained:

$$
\begin{gathered}
W=32.144-7.076 \cdot S-0.004 \omega+7.62 \cdot F-0.066 \cdot U-6.623 \cdot P \\
R^{2}=0.888
\end{gathered}
$$

Note, that the use in the program "SPSS Statistics" the "Step-by-step selection" option and the model selection with maximum $R^{2}$ gives almost the same equation.

The sign (character) of the coefficient for the parameters $S, \omega, F, U, P$ in the equation (1) shows a positive or negative effect on moisture has this parameter. As you can see, an increase in the parameters $S, U, \omega$ leads to a decrease in moisture, they have a negative coefficient. The increase of the parameters $R, F$ adversely affects the moisture. It is not advisable to analyze the influence of the parameters on the value of the coefficients, since they are nonequilibrium, for example, $\omega$ is measured in thousands of units, and $P$ in hundredths of units.

Equation (1) has a low approximation, $R^{2}=0.888$. The value of $R^{2}$ can be increased if you build a more complex regression equation, for example, in the form of a full quadratic form. In favor of a more complex regression equation says installed above the fact that all private pair correlations of $W(F) W(P), W(S), W(U), W(\omega)$ have weakly-nonlinear character. That is, the generalized regression equation must include nonlinear terms.

To construct the regression dependence of $W$ on all factors, we set the target function as a full quadratic form. To reduce the number of terms in the regression equation, we used "SPSS Statistics" program the "Step-by-step selection" option: METHOD=STEPWISE $\left(S, \omega, F, U, P, S^{2}, S \omega, S F, S U, S P, \omega^{2}, \omega F, \omega U, \omega P, F^{2}, F U, F P, U^{2}, U P, P^{2}\right)$.

The selection criterion was chosen based on the significance (probability) of F-statistics: inclusion - 0.05 , removal -0.1 . The confidence interval level of $95 \%$ was chosen for the 
regression coefficients.

The calculation obtained 13 regression models for which $R^{2}$ varies from 0.822 to 0.998 . The selected model with the highest accuracy of approximation in terms of $R^{2}$, the equation for the regression has the form:

$$
\begin{aligned}
W=30.361- & 0.013 \cdot \omega+2.32 \cdot 10^{-6} \cdot \omega^{2}-256.855 \cdot F \cdot P-0.065 \cdot F \cdot U-92.519 \cdot S \cdot P+ \\
& +1972.17 \cdot P^{2}+3.241 \cdot S^{2}-3.759 \cdot S+29.488 F^{2}, \quad R^{2}=0.996
\end{aligned}
$$

Thus, when using the method of step-by-step selection of 20 variables, 9 variables were included in the model (2). In this case, it involves all five variable factors $-S, \omega, F, U, P$ and takes into account the nonlinearity that makes each of them. The approximation accuracy of the generalized regression equation (2) compared to (1) increased significantly, $R^{2}$ increased from 0.888 to 0.996 .

The obtained regression models (1) and (2) make possible to predict the change in moisture for different combinations of device parameters. In this case, the model (1) gives an approximate estimate, and (2) - sufficiently accurate.

For example, we estimate the effect of drying area $S$ on moisture.

According to equation (1), from the common range of variation of the parameters, as optimal, it is advisable to choose $P$ and $F$ the minimal value, and $U$ and $\omega$ - the maximum. These parameters are: $P=0.063 \mathrm{MPa}, F=0.5 \mathrm{kN}, U=100 \mathrm{~V}$ and $\omega=3000 \mathrm{rpm}$. For these fixed parameters, the dependences of $W(S)$ are obtained from the regression equations (1) and (2), which are shown in Figure 3.

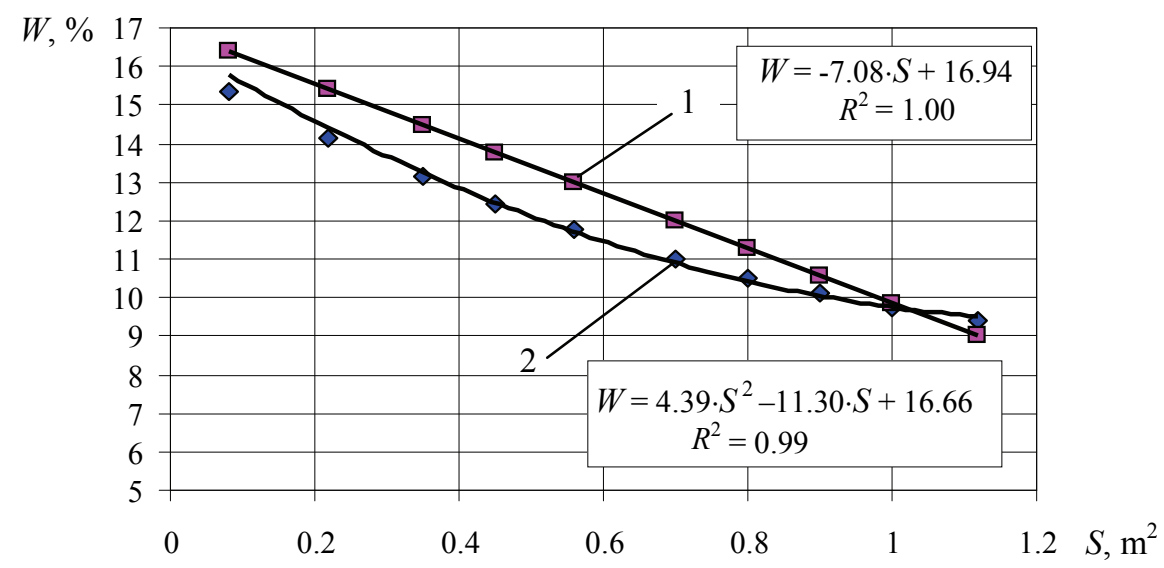

Fig. 3. The dependence of the moisture content $W$ of the area of drying in the range $S=0.08-$ $1.12 \mathrm{~m}^{2}$ at $P=0.063 \mathrm{MPa}, F=0,5 \mathrm{kN}, U=100 \mathrm{~V}, \omega=3000 \mathrm{rpm}, W_{0}=30 \%: 1-$ at the approximate regression model (1); 2 - at adequate regression model (2).

The approximate regression model (1) gives a rough estimate of the dependence of moisture on the drying area, it is expressed by a linear equation:

$$
W=16.94-7.08 \cdot S
$$

The regression model (2) has a high degree of approximation, the dependence of moisture changes with increasing drying area square has the form of a nonlinear quadratic function:

$$
W=16.66-11.3 \cdot S+4.39 \cdot S^{2}
$$

Equations (3) and (4) are applicable in the drying area range $S=0.08-1.12 \mathrm{~m}^{2}$ at 
$P=0.063 \mathrm{MPa}, F=0.5 \mathrm{kN}, U=100 \mathrm{~V}$ and $\omega=3000 \mathrm{rpm}$.

When comparing the calculation of equation (3) with that of equation (4), the maximum difference in moisture is $1.3 \%$ (Fig. 3). Such discrepancy may be significant, so equation (1) can only serve as an approximate estimate.

For practical application, it is advisable to use a regression model (2) as having a high accuracy of approximation. Model (2) allows to determine the final moisture content of the product at the initial moisture $W_{0}=30 \%$, angle of inclination of the working body $\alpha=5^{\circ}$ and change the device parameters in the ranges: vibration frequency of the exciter $\omega=1500$ - $3000 \mathrm{rpm}$, the magnitude of the disturbing force of the vibration exciter $F=0.5-0.8 \mathrm{kN}$, the intensity of the electric field $U=25-100 \mathrm{~V}$, pressure in the vacuum chamber $P=0.063$ $-0.1 \mathrm{MPa}$.

\section{Summary}

Processing of ash and slag waste from thermal power plants is constrained by the need for dehydration of microfine products of ash storage facilities. Drying device with the integrated effects of vibration, electro-osmosis and vacuum was developed. The results of experimental studies on the dehydration of ash and slag waste (fly ash) of the NovoKramatorsk coal power plant with a size of $+0.63-0.05 \mathrm{~mm}$ are presented. They showed that, depending on the parameters of the device, moisture can be reduced from $30 \%$ to $9 \%$. The analysis of the experiments showed that the partial pair correlations of moisture with any of the device parameters are of a weak nonlinear character. Accurate and approximate regression models have been developed for the practical evaluation of the final moisture content of the product depending on all the parameters of the device. The equations cover the following range of device parameters: vibration frequency of the vibro-exciter $\omega=1500$ $-3000 \mathrm{rpm}$, the magnitude of the disturbing force of the vibro-exciter $F=0.5-0.8 \mathrm{kN}$, the intensity of the electric field $U=25-100 \mathrm{~V}$, the pressure in the vacuum chamber $P=0.063$ - 0.1 MPa. Regression equations allow us to estimate the final moisture content of the product at the initial moisture $W_{0}=30 \%$ and the angle of inclination of the working body $\alpha=5^{\circ}$. The developed device of complex action for dehydration of fine raw materials is promising for use in technologies of processing of products of thermal power station ash storage, it provides a reduction in moisture content of ash and slag waste from $30 \%$ to $9 \%$.

\section{References}

1. Efimov, N.N., Yatsenko, E.A., Smoliy, V.A. (2011). Ecological aspects and problems of utilization and recycling of ash and slag wastes of thermal power plants. Ekologiya prom. proizvodstva, 2, 40-44

2. Cherepanov, A.A., Kardash, V.T. (2009). Complex processing of ash and slag wastes of TPS (results of laboratory and semi-industrial tests). Geologiya $i$ poleznyye iskopayemyye Mirovogo okeana, 2, 98-115

3. Nadutyi, V.P., Sevastianov, V.S., Kostyria, S.V. (2016). Justification of expediency of complex processing of fly ash of thermal power plants. Geotekhnichna mekhanika, $131,59-66$

4. The use of ash and slag waste. Domestic bibliography 1980 - 2012. (2018). Available at http://www.prometeus.nsc.ru/partner/zarubin/ash2.ssi

5. Tselykovskiy, Yu.K. (2006). Experience in the disposal of ash and slag waste in European countries and the possibility of its use in Russian conditions. Energetik, 10, 29-33

6. Andreyeva, N.G. (2011). The problem of disposing of ash and slag waste TPS, and 
possible ways of their solution. Polzunovskiy vestnik, 4-2, 164-166

7. Ehorov P.A., Bereznyak A.A. (2007). Technology of processing of ashes of thermal power plants. Zbahachennya korysnykh kopalyn: Naukovyi Visnyk Natsionalnoho Hirnychoho Universytetu, 29, 224-227

8. Nazimenko, Ye.I., Garkovenko, Ye.Ye. (2003). Intensification of filtration processes of fine coal slurries by pulsed fields. Mining information and analytical Bulletin, Moskva, 2, 48-50

9. Nadutyi, V.P., Suhariev, V.V., Kostyria, S.V. (2014). Prystriy dlya znevodnennya [Dehydration device]. Patent No 92897, Ukraine

10. A. Buyul, P. Tsefel. (2005). SPSS: the art of information processing. Analysis of statistical data and restoration of hidden patterns, St. Petersburg 